\title{
Plasma exosomes are enriched in Hsp70 and modulated by stress and cortisol in rainbow trout
}

\author{
Erin Faught ${ }^{\dagger}$, Lynsi Henrickson and Mathilakath M Vijayan ${ }^{\dagger}$ \\ Department of Biology, University of Waterloo, Waterloo, Ontario, Canada \\ ${ }^{\dagger}$ (E Faught and M M Vijayan are now at Department of Biological Sciences, University of Calgary, \\ Alberta, Canada)
}

Correspondence
should be addressed
to M M Vijayan
Email
matt.vijayan@ucalgary.ca

\begin{abstract}
Exosomes are endosomally derived vesicles that are secreted from cells and contain a suite of molecules, including proteins and nucleic acids. Recent studies suggest the possibility that exosomes in circulation may be affecting recipient target cell function, but the modes of action are unclear. Here, we tested the hypothesis that exosomes are in circulation in fish plasma and that these vesicles are enriched with heat shock protein 70 (Hsp70). Exosomes were isolated from rainbow trout (Oncorhynchus mykiss) plasma using differential centrifugation, and their presence was confirmed by transmission electron microscopy and the exosomal marker acetylcholinesterase. Plasma exosomes were enriched with Hsp70, and this stress protein was transiently elevated in trout plasma in response to a heat shock in vivo. Using trout hepatocytes in primary culture, we tested whether stress levels of cortisol, the principle corticosteroid in teleosts, regulates exosomal $\mathrm{Hsp} 70$ content. As expected, a 1 -h heat shock $\left(+15^{\circ} \mathrm{C}\right.$ above ambient) increased Hsp70 expression in hepatocytes, and this led to higher Hsp70 enrichment in exosomes over a 24-h period. However, cortisol treatment significantly reduced the expression of $\mathrm{Hsp} 70$ in exosomes released from either unstressed or heatshocked hepatocytes. This cortisol-mediated suppression was not specific to $\mathrm{Hsp} 70$ as beta-actin expression was also reduced in exosomes released from hepatocytes treated with the steroid. Our results suggest that circulating Hsp70 is released from target tissues via exosomes, and their release is modulated by stress and cortisol. Overall, we propose a novel role for extracellular vesicular transport of Hsp70 in the organismal stress response.
\end{abstract}

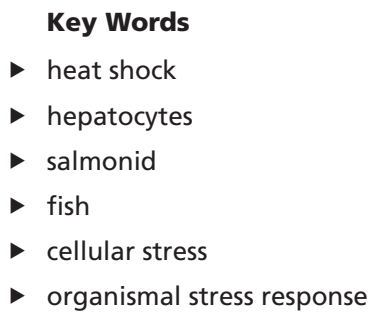

Journal of Endocrinology (2017) 232, 237-246

\section{Introduction}

Recent studies have established exosomes, membranebound vesicles of endosomal origin, as important mediators of intercellular signaling (reviewed by Colombo et al. 2014). These extracellular vesicles are approximately $30-100 \mathrm{~nm}$ in diameter and contain protein and nucleic acids, reflective of their cell of origin. Despite differences in cell types, exosomes have several common characteristics, including enrichment of sphingomyelin and tetraspanins (Rana \& Zoller 2013, Andreu \& Yáñez-Mó 2014) and heat shock proteins (Hsps), notably Hsp70 and Hsp90 (Thery et al. 2001, Clayton et al. 2005, Lancaster \& Febbraio 2005, McCready et al. 2010). Recent studies suggest that

Published by Bioscientifica Ltd 
exosomes from one cell type may communicate with a different recipient cell (Mittelbrunn et al. 2011). Most of these studies have utilized mammalian cell systems, and there is a paucity of information on exosome dynamics in whole organisms, as well as in lower vertebrates. A recent study, using a proteomics approach, reported Hsp70 and Hsp90 in exosomes in conditioned media derived from Atlantic salmon (Salmo salar) head kidney leukocytes (Iliev et al. 2010).

Heat shock proteins are a family of highly conserved proteins and play a key role in protein homeostasis during cellular stress (Deane \& Woo 2011). In fish, the intracellular induction of Hsps, in particular Hsp70, has been well characterized in response to a plethora of stimuli (Iwama et al. 1999, Basu et al. 2002, Vijayan et al. 2010, Deane \& Woo 2011). Also, studies have shown that cortisol, the primary circulating corticosteroid in teleost, modulates target tissue Hsp70 expression in fishes, thereby linking the cellular stress response with the organismal stress response (Ackerman et al. 2000, Basu et al. 2001, Boone \& Vijayan 2002, De Boeck et al. 2003). Recent studies suggest that Hsp70 may also be released extracellularly in fishes, but the secretory pathways are far from clear (Illiev et al. 2010, Zhang et al. 2011). Hsp70 lacks the leader sequence necessary to be classically exported from the cell (Mambula et al. 2007), leading to the proposal that they are exported out of the cell in exosomes (Hunter-Lavin et al. 2004, Lancaster \& Febbraio 2005). Although this has been confirmed in exosomes derived from human blood plasma (Kalra et al. 2013, Cheng et al. 2014, Vicencio et al. 2015) and mammalian cell culture media (Lancaster \& Febbraio 2005, Merendino et al. 2010, Takeuchi et al. 2015), such studies are lacking in lower vertebrates (Iliev et al. 2010).

A recent study revealed that exosomal Hsp70 transmission across cell types may be a key mechanism for the maintenance of organismal proteostasis in Drosophila melanogaster (Takeuchi et al. 2015). To this end, Hsp70positive exosomes have been shown to be cardioprotective by initiating intracellular secondary signaling cascades involving toll-like receptor 4 (Vicencio et al. 2015). To the best of our knowledge, this has yet to be shown in vivo in vertebrates. Given that neither circulating exosomes nor plasma Hsp70 have been reported in fish, we tested the hypothesis that circulating Hsp70 in fish are enriched in exosomes using rainbow trout (Oncorhynchus mykiss) as a model. To date, no study has addressed whether corticosteroids affect exosome release and/or packaging in any organism. As corticosteroid is a key player in the organismal stress response, we also tested the possibility that this hormone may modulate exosomal Hsp70 expression using trout hepatocytes in primary culture (Faught \& Vijayan 2016).

\section{Materials and methods}

\section{Experimental fish}

In vivo heat shock study was carried out with juvenile rainbow trout ( $110 \pm 20 \mathrm{~g}$ body mass) obtained from Alma Research Station (Alma, Ontario, Canada) and maintained at the University of Waterloo Aquatic Facility (Waterloo, Ontario, Canada). The fish used for exosome experiments (plasma exosomes and hepatocyte exosomes) were juvenile rainbow trout $(150 \pm 25 \mathrm{~g}$ body mass $)$ obtained from Allison Creek Brood Trout Hatchery Station (Crowsnest Pass, Canada) and maintained at the University of Calgary Animal Care Facility (Calgary, Alberta). Fish were maintained at $12 \pm 1^{\circ} \mathrm{C}$ on a 12-h light: 12 -h darkness cycle and fed once daily to satiety with commercial trout pellet (Martin Mill, Elmira, Canada). The fish were acclimated for 2 weeks before the experiments. All experiments were approved by the Animal Care and Use Committee at the University of Waterloo and the University of Calgary and were in accordance with guidelines established by the Canadian Council for Animal Care.

\section{Whole animal study}

To assess the circulating Hsp70 levels in response to an acute heat shock, groups of 12 fish each were separated into four $100 \mathrm{~L}$ tanks in a static system. Water in two tanks was heated to a temperature of approximately $25^{\circ} \mathrm{C}$ $\left(+12^{\circ} \mathrm{C}\right.$ above ambient), whereas that in other two tanks was maintained at ambient temperature $\left(13^{\circ} \mathrm{C}\right)$. Fish were subjected to the $+12^{\circ} \mathrm{C}$ heat shock for one hour after which they were brought back to $13^{\circ} \mathrm{C}$ within $15 \mathrm{~min}$. Six fish from each of the heat-shocked and control (no heat shock) groups were sampled immediately after heat shock $(1 \mathrm{~h})$ and at $4 \mathrm{~h}$ and $24 \mathrm{~h}$ after heat shock. Fish were quickly netted and killed with an overdose of 2-phenoxyethanol (1:1000 well water; Sigma). Pieces of liver and blood samples were collected at each time point. Blood was collected in tubes containing EDTA $(5 \mathrm{mM}$ in Hank's medium) and centrifuged for five min at $3000 \boldsymbol{g}$ to separate the plasma. All samples were stored at $-80^{\circ} \mathrm{C}$ for analysis later. 


\section{Hepatocyte study}

Trout hepatocytes were isolated as described previously using in situ collagenase perfusion (Boone \& Vijayan 2002). Hepatocyte viability was $>95 \%$. Cells were suspended in L15 (Gibco, Life Technology) medium and plated in six-well tissue culture plates (Sarstedt, Inc., Newton, MA, USA) at a density of 1.5 million cells/well ( 0.75 million cells $/ \mathrm{mL})$. Cells were allowed to recover for at least an hour, and then treated with either a vehicle ( $0.01 \%$ ethanol) or cortisol (100 and $1000 \mathrm{ng} / \mathrm{mL})$. Treated cells were maintained at $11^{\circ} \mathrm{C}$ for $24 \mathrm{~h}$ at which time the L15 media was replaced and cells were again treated as previously. The cells either remained at $11^{\circ} \mathrm{C}$ or were subjected to a $1 \mathrm{~h}$ heat shock $\left(+15^{\circ} \mathrm{C}\right.$ above ambient) and allowed to recover for $24 \mathrm{~h}$. This experimental protocol was previously used in Boone \& Vijayan (2002) to assess the effect of cortisol on Hsp70 expression in trout hepatocytes. Cells were collected and media was removed and fractionated as described below to obtain exosomes. Experiments were repeated with hepatocytes from five independent fish.

\section{Exosome fractionation}

Plasma exosomes were isolated by differential centrifugation as described previously for fish cells (Iliev et al. 2010) and mammalian cell supernatants (Thery et al. 2006). Briefly, blood from each fish was collected in tubes containing a final concentration of $5 \mathrm{mM}$ EDTA and centrifuged at $500 \boldsymbol{g}$ to remove red blood cells and peripheral blood leukocytes (Fig. 1A). An aliquot of the plasma was sampled (total plasma $t=0$ ), and the remaining plasma was then subjected to two sequential centrifugation steps to remove cell debris: $1200 \boldsymbol{g}$ for $20 \mathrm{~min}$ and $10,000 \mathrm{~g}$ for $30 \mathrm{~min}$. This fractionated plasma was further spun at $150,000 \mathrm{~g}$ using an ultracentrifuge (Beckman) for $120 \mathrm{~min}$ to pellet the exosomes (Fig. 1A). The exosome pellet was resuspended in $1 \times$ PBS $(20 \mu \mathrm{L} / 1 \mathrm{~mL}$ of plasma or $10 \mu \mathrm{L} / 1 \mathrm{~mL}$ of media fractionated). The supernatants and the exosome pellets were stored separately at $-80^{\circ} \mathrm{C}$ for later analysis. The fractionation of exosomes from supernatants of hepatocyte cultures was also carried out exactly as described previously.

\section{Transmission electron microscopy (TEM)}

Freshly isolated exosomes in PBS were transferred to carbon-coated formvar films on copper-grids for $5 \mathrm{~min}$, washed in distilled water for $20 \mathrm{~s}$ and treated with $1.8 \%$ methylcellulose $/ 0.3 \%$ uranyl acetate for $4 \mathrm{~min}$ before drying. The samples were examined with a Tecnai F20 Transmission Electron Microscope (FEI. Hillsboro, OR, USA).

\section{Hsp70 immunoblotting}

Protein quantification, SDS-PAGE and western blotting were performed as described previously (Boone \& Vijayan 2002). Total plasma protein concentration was determined by the bicinchoninic acid (BCA) method using
A

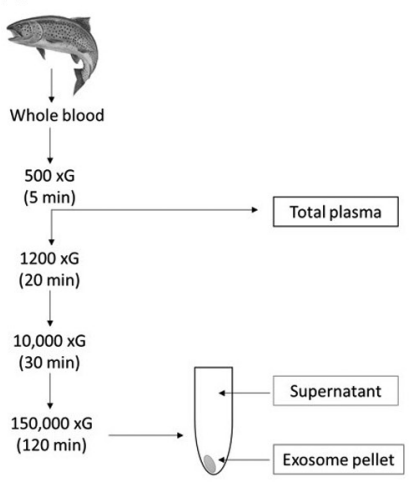

B

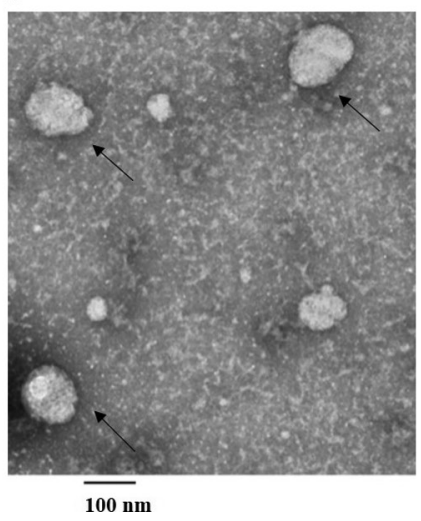

C

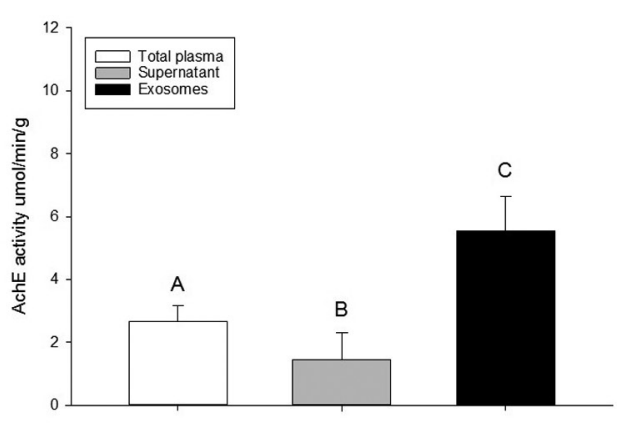

Figure 1

Exosome identification in plasma. Plasma from rainbow trout was fractionated by differential centrifugation to confirm the presence of exosomes (A). Exosomes were confirmed by TEM from freshly isolated plasma ( $\mathrm{B}$; arrows indicate exosomes; the scale bar denotes $100 \mathrm{~nm}$ ). The average size as measured over 50 vesicles was $53.8 \mathrm{~nm}( \pm 3.5 \mathrm{~nm})$. Acetylcholinesterase (AChE) enzyme enrichment of the plasma exosomes $(C ; n=6$ independent fish) was confirmed by comparing their presence in the plasma and the supernatant; bars with different letters are significantly different $(P<0.05$, one-way RM ANOVA). 
bovine serum albumin standards. Plasma and hepatocyte homogenate samples were diluted to $1 \mathrm{mg} / \mathrm{mL}$ in a SDS sample buffer (0.06 M Tris- $\mathrm{HCl}(\mathrm{pH} 6.8), 20 \%$ (v/v) glycerol, $0.02 \%(\mathrm{w} / \mathrm{v})$ SDS, $0.025 \%(\mathrm{w} / \mathrm{v})$ bromophenol blue and $5 \%$ B-mercaptoethanol). Samples were loaded on an $8 \%$ polyacrylamide gels with a molecular marker to confirm protein mass (Frogga Bio, Mississauga, Canada). Proteins were separated (200V for $50 \mathrm{~min}$; Mini Protean III (BioRad) using a discontinuous buffer. The separated proteins were transferred to a $0.45 \mu \mathrm{m}$ pore size nitrocellulose membrane (Bio-Rad) using a Transblot SD Semi-Dry Electrophoretic Transfer Cell (Bio-Rad) and transfer buffer (25 mM Tris (pH 8.3), $192 \mathrm{mM}$ glycine, $20 \% \mathrm{v} / \mathrm{v}$ methanol). Equal loading and transfer efficiency was confirmed by Ponceau S. Blots were probed for $1 \mathrm{~h}$ at RT with antisalmon Hsp70 (Boone \& Vijayan 2002; StressMarq (SPC313), Victoria, Canada) diluted to 1:1000, followed by anti-rabbit IgG-conjugated horseradish peroxidase (HRP) (1:3000; Bio-Rad). The protein band was detected using ECL Plus Western blotting detection reagent (Bio-Rad) and scanned using the Syngene G-Box Imager (Syngene, Fredrick, USA). Protein band intensity was quantified using ImageJ. Densometric values for plasma and exosome fractions were normalized to total lane protein detected with Ponceau S. Equal loading of hepatocyte samples was confirmed by incubation of membranes with Cy3-conjugated monoclonal mouse beta-actin antibody (Sigma, 1:1000) for $1 \mathrm{~h}$ at RT (Dindia et al. 2013). There was no change in beta-actin expression among treatments (data not shown).

\section{Hsp70 enzyme-linked immunosorbent assay (ELISA)}

Measurement of plasma Hsp70 by ELISA was carried out using a competitive sandwich ELISA adapted from Specker \& Anderson (1994). Chinook salmon Hsp70 recombinant protein (Enzo Life Sciences (ADI-SPP-763-D), Exeter, UK) was used to coat wells, to which was added previously incubated samples or standards (1:1 ratio of homogenate to polyclonal rabbit anti-salmon Hsp70 primary antibody $(1: 100,000)$; StressMarq (SPC-313)). After overnight incubation, wells were washed and a horseradish peroxidase-conjugated goat anti-rabbit secondary antibody (1:5000; Bio-Rad) diluted in 5\% skim milk was added to each well. After a 1-h incubation and washings, the detection reagent was added $(41 \mathrm{mM}$ TMB in $200 \mathrm{mM}$ potassium citrate, $\mathrm{pH} 4$ ). After $1 \mathrm{~h}$, the reaction was stopped with $8.5 \mathrm{M}$ acetic acid in $0.5 \mathrm{M}$ sulfuric acid. Wells were read at $450 \mathrm{~nm}$ using a multi-well spectrophotometer (VersaMax, Molecular Devices, Sunnyvale, USA).

\section{Plasma cortisol}

Plasma cortisol levels were analyzed using a $3 \mathrm{H}$-cortisol radioimmunoassay that was validated for rainbow trout plasma as described previously (Sandhu \& Vijayan 2011).

\section{Enzyme activity}

To assess cell leakage due to heat shock, the activity of the intracellular enzymes in the plasma (LDH and AspAT) was measured in $50 \mathrm{mM}$ imidazole-buffered enzyme reagent ( $\mathrm{pH} 7.4)$ at room temperature $\left(23.5-24.5^{\circ} \mathrm{C}\right)$ by continuous spectrophotometry at $340 \mathrm{~nm}$ using a microplate reader as described previously (Ings et al. 2011).

Acetylcholinesterase (AChE) activity was measured as a marker of exosome release (Johnstone et al. 1987). The AChE protocol was adapted from Johnstone and coworkers (Johnstone et al. 1987) and Multhoff (2007) and measured at $415 \mathrm{~nm}$ for $30 \mathrm{~min}$ at room temperature. The extinction coefficient used to calculate AChE activity was 13,600 M/cm (DNTB, Ellman 1958).

- Lactate dehydrogenase (LDH: EC 1.1.1.27): $0.12 \mathrm{mM}$ NADH and reaction started with $25 \mathrm{mM}$ sodium pyruvate.

- Aspartate aminotransferase (AspAT: EC 2.6.1.1): $7 \mathrm{mM}$ $\alpha$-ketoglutarate, $0.025 \mathrm{mM}$ pyridoxal 5-phosphate, $0.12 \mathrm{mM} \mathrm{NADH}$ and $8 \mathrm{U} / \mathrm{mL}$ malate dehydrogenase; reaction started with $40 \mathrm{mM}$ aspartic acid.

- Acetylcholinesterase (AChE: EC 3.1.1.7). $0.1 \mathrm{mM}$ 5,5-dithio-bis-(2-nitrobenzoic acid) (DNTB/Ellman's reagent). The reaction was started with $10 \mathrm{mM}$ acetylthiocholine.

\section{Statistical analysis}

Statistical analysis was carried out with SigmaPlot (Systat Software Inc, San Jose, USA). Exosome characterization of AChE and Hsp70 enrichment utilized a repeated measures (RM) one-way ANOVA. Significant differences were compared using the Holm-Sidak post hoc test with the level of significance set at $P<0.05$. The in vivo experiment utilized a two-way ANOVA. The in vitro hepatocyte experiment utilized a RM two-way ANOVA. The data were transformed, wherever necessary, to meet the assumptions of homogeneity of variance, although non-transformed data are shown in the figures. Results are presented as mean \pm standard error of mean (s.E.M.) for all groups, and the sample size is indicated in the figure legends.

Published by Bioscientifica Ltd 


\section{Results}

\section{Plasma exosome characterization}

Exosomes were isolated from trout plasma by differential centrifugation as outlined in Fig. 1A. The exosomes were confirmed microscopically using TEM (Fig. 1B) and enzymatically using acetylcholinesterase (AChE) (Fig. 1C). Exosomes in trout plasma were on an average $54 \pm 4 \mathrm{~nm}$ in diameter ( $n=50$ exosomes; Fig. 1B). AChE activity was significantly enriched in the exosomes compared to the supernatant and total plasma fractions (Fig. 1C; $P<0.001$, RM one-way ANOVA). The supernatant fraction had significantly less AChE activity compared to the total plasma fraction $(P<0.05$; Fig. 1C).

\section{Hsp70 in plasma exosomes}

Hsp70 was significantly enriched in the exosomes compared to the supernatant and plasma fractions (Fig. 2). There was a >6-fold enrichment of Hsp70 expression in the exosomes compared to total plasma $(P<0.005$; RM one-way ANOVA) and the supernatant $(P<0.001)$ fractions (Fig. 2). There was no significant difference
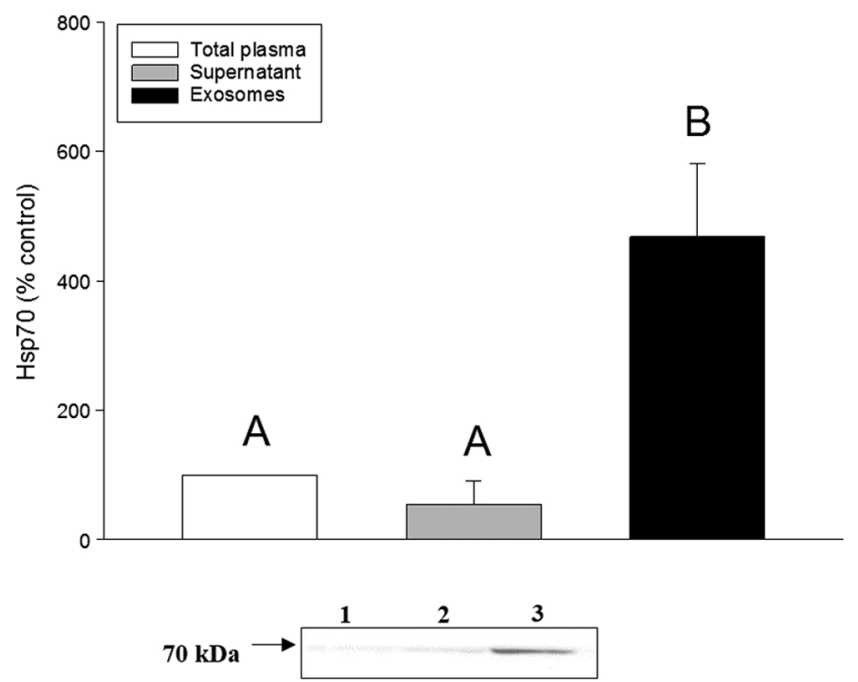

\section{Figure 2}

Hsp70 enrichment in the exosome fraction of plasma. Freshly isolated exosomes from trout plasma were examined for Hsp70 protein expression by immunodetection (polyclonal rabbit anti-salmonid Hsp70: 1:1000). Hsp70 enrichment in exosomes (3) was confirmed by comparing this protein expression in the plasma (1) and the supernatant (2). Both the supernatant and exosome Hsp70 expression are expressed as \% of the protein expression in the total plasma (\% control). Values represent means \pm S.E.M. ( $n=6$ independent fish); bars with different letters are significantly different $(P<0.05$, one-way ANOVA). A representative western blot of Hsp70 expression for these samples is shown below the histogram. in Hsp70 expression between the total plasma and the supernatant fractions.

\section{Hepatocyte exosome release}

Intracellular hepatocyte Hsp70 levels increased 7-fold after heat shock compared to controls (Fig. 3A; two-way ANOVA; $\left.F_{1,16}=45.68 ; P<0.001\right)$. Cortisol treatment had no significant effect $\left(F_{2,16}=0.17 ; P<0.8\right)$ on hepatocyte Hsp70 expression (Fig. 3A). There was no significant interaction between cortisol treatment and heat shock $\left(F_{2,16}=0.012 ; P=0.99\right)$.

Exosome Hsp70 expression was also significantly elevated after heat shock by 20-fold compared to controls (Fig. 3B; two-way ANOVA; $F_{1,16}=29.2 ; P<0.001$ ). Cortisol treatment significantly reduced the amount of Hsp70-positive exosomes $\left(F_{2,16}=4.73 ; P=0.024\right)$. There was no significant interaction between heat shock and cortisol treatment $\left(F_{2,16}=0.32 ; P=0.7\right)$. Multiple comparison analysis (Holm-Sidak method) revealed that $1000 \mathrm{ng} / \mathrm{mL}$ of cortisol significantly reduced Hsp70positive exosomes $(P=0.023)$, whereas there was no significant difference between control and the $100 \mathrm{ng} / \mathrm{mL}$ cortisol group $(P<0.2)$.

There was no effect of heat shock on beta-actin expression in exosomes (Fig. 3C; two-way ANOVA; $\left.F_{1,16}=1.61 ; \quad P=0.22\right)$. Cortisol treatment significantly reduced beta-actin expression in exosomes (two-way ANOVA; $\left.F_{2,16}=17.0 ; P<0.001\right)$. There was no significant interaction between heat shock and cortisol treatment on exosomal beta-actin expression (two-way ANOVA; $\left.F_{2,16}=0.16 ; \quad P<0.9\right)$. Treatment with cortisol at both $1000 \mathrm{ng} / \mathrm{mL} \quad(P=0.002) \quad$ and $100 \mathrm{ng} / \mathrm{mL} \quad(P=0.013)$ significantly reduced beta-actin expression in the exosomes compared to the controls (pairwise multiple comparison; Holm-Sidak method). Non-heat-shocked cells released exosomes with significantly lower betaactin expression at both $1000 \mathrm{ng} / \mathrm{mL}(P=0.012)$ and $100 \mathrm{ng} / \mathrm{mL}(P=0.013) \quad$ (pairwise multiple comparison) cortisol groups. Similarly, heat-shocked cells also released exosomes that had significantly reduced beta-actin expression in the $1000 \mathrm{ng} / \mathrm{mL}(P=0.002)$ and $100 \mathrm{ng} / \mathrm{mL}$ $(P=0.007)$ cortisol groups compared to the control group (pairwise multiple comparison).

\section{Whole animal study}

Plasma cortisol levels were significantly higher in the heat shock group compared to the control group (Table 1;

Published by Bioscientifica Ltd. 
A

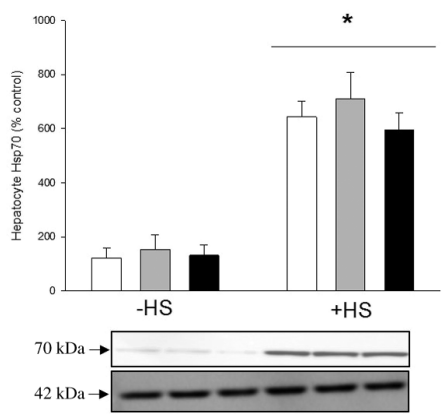

B

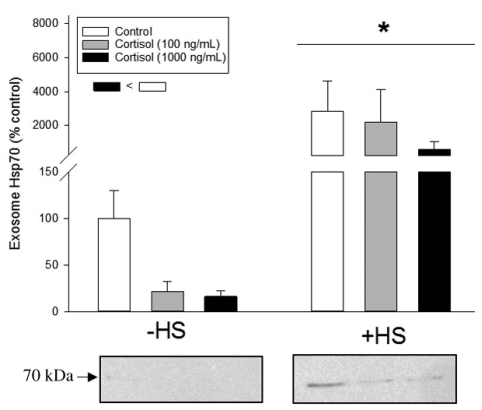

C

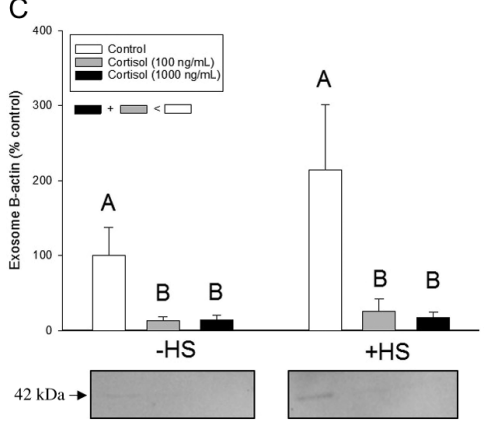

Figure 3

Hepatocyte exosome release. Primary culture of hepatocytes were exposed to a $1 \mathrm{~h}$ heat shock $\left(+15^{\circ} \mathrm{C}\right.$ above ambient) and allowed to recover for $24 \mathrm{~h}$ at ambient temperature $\left(11^{\circ} \mathrm{C}\right)$. Cells were treated with either a vehicle control $(0.01 \%$ ethanol) or stressed level of cortisol $(100 \mathrm{ng} / \mathrm{mL} \mathrm{and} 1000 \mathrm{ng} / \mathrm{mL})$. Intracellular Hsp70 expression was confirmed by immunodetection ( $\mathrm{A} ; n=5$ independent fish hepatocytes; polyclonal rabbit anti-salmonid Hsp70: 1:1000; $t$-test). A representative western blot of $\mathrm{Hsp} 70$ and beta-actin $(42 \mathrm{kDa}$ ) expression in these samples is shown below the histogram. Media from these cultured hepatocytes was fractionated and the expression of Hsp70 (B) and beta-actin (C) in exosomes confirmed by immunodetection ( $n=3-4$ independent fish hepatocytes); bars with different letters are significantly different $(P<0.05$, two-way ANOVA). Treatment effects are shown as an inset in each figure. A representative western blot of $\mathrm{Hsp} 70$ and beta-actin $(42 \mathrm{kDa})$ expression in these samples is shown below their respective histograms.

two-way ANOVA; $F_{1,30}=7.1 ; P<0.02$ ), but there was no time effect (Table 1 ; two-way ANOVA; $F_{2,30}=2.48 ; P=0.10$ ). Multiple comparisons (Holm-Sidak method) revealed that cortisol was significantly higher in the heat shock group at $4 \mathrm{~h}$ after heat shock $(P=0.002)$ compared to the control group. Cortisol levels in the control fish (absence of heat shock) were lower at $4 \mathrm{~h}$ post-stressor compared to the control fish sampled at $1 \mathrm{~h}$ post-stressor $(P=0.015)$.

There was no significant effect of heat shock on plasma protein, $\mathrm{LDH}$ or AspAT content at any time point compared to the control group (Table 1; two-way ANOVA).

Given the low Hsp70 expression in non-fractionated plasma, we quantified plasma Hsp70 levels using an ELISA. There was a statistically significant interaction between the time and treatment (heat shock) on plasma Hsp70 levels (Fig. 4A; two-way ANOVA; $F_{2,17}=4.03 ; P<0.04$ ). Multiple comparison analysis (Holm-Sidak method) showed that there was a significant increase in plasma
Hsp70 levels in heat-shocked fish compared to controls at $4 \mathrm{~h}$ after heat shock $(P=0.013)$. Fish that were not exposed to heat shock (control) had no difference in levels of Hsp70 over time. There was a time effect in the heat shock group with significantly higher levels of plasma Hsp70 at $4 \mathrm{~h}$ compared to fish sampled at $1 \mathrm{~h}(P=0.010)$ and $24 \mathrm{~h}$ $(P=0.007)$ after heat shock.

There was a statistically significant interaction between time and treatment (heat shock) on liver Hsp70 expression (Fig. $4 \mathrm{~B}$; two-way ANOVA; $F_{2,30}=7.6 ; P=0.002$ ). There was no significant difference in liver Hsp70 expression at $1 \mathrm{~h}(P=0.32)$, but at $4(P<0.001)$ and $24 \mathrm{~h},(P<0.0001)$ the protein expression was significantly higher compared to their respective controls (Fig. 4B). There was no change in liver Hsp70 expression in control fish over $24 \mathrm{~h}(P=0.6)$, whereas heat-shocked fish had significantly higher Hsp70 expression at $4(P=0.004)$ and $24 \mathrm{~h}(P=0.002)$ after heat shock compared to the control group.

Table 1 Plasma protein, enzymes and cortisol levels. Plasma was sampled from trout that were either unexposed (control) or exposed to a 1-h heat shock $\left(+12^{\circ} \mathrm{C}\right.$ above ambient temperature) and then allowed to recover at ambient temperature $\left(13^{\circ} \mathrm{C}\right)$. Samples were collected at 1,4 and $24 \mathrm{~h}$ after heat shock.

\begin{tabular}{|c|c|c|}
\hline Time post-stress $(\mathrm{h})$ & Treatment & Protein $(\mathrm{mg} / \mathrm{mL})$ \\
\hline \multirow[t]{2}{*}{1} & Control & $23.34 \pm 2.16$ \\
\hline & Heat shock & $20.82 \pm 0.80$ \\
\hline \multirow[t]{2}{*}{4} & Control & $19.79 \pm 4.38$ \\
\hline & Heat shock & $22.45 \pm 0.23$ \\
\hline \multirow[t]{2}{*}{24} & Control & $19.95 \pm 2.02$ \\
\hline & Heat shock & $23.81 \pm 1.02$ \\
\hline
\end{tabular}

\begin{tabular}{c} 
AsAT $(\mathrm{U} / \mathrm{g})$ \\
\hline $0.34 \pm 0.03$ \\
$0.36 \pm 0.02$ \\
$0.26 \pm 0.03$ \\
$0.33 \pm 0.03$ \\
$0.26 \pm 0.01$ \\
$0.36 \pm 0.04$
\end{tabular}

\begin{tabular}{c}
\hline LDH $(\mathrm{U} / \mathrm{g})$ \\
\hline $1.95 \pm 0.21$ \\
$2.17 \pm 0.23$ \\
$2.34 \pm 0.36$ \\
$2.35 \pm 0.19$ \\
$1.92 \pm 0.21$ \\
$2.11 \pm 0.14$ \\
\hline
\end{tabular}

\begin{tabular}{c} 
Cortisol $(\mathrm{ng} / \mathrm{mL})$ \\
\hline $27.9 \pm 5.4$ \\
$26.6 \pm 3.1$ \\
$14.0 \pm 2.5^{\#}$ \\
$29.5 \pm 4.2^{*}$ \\
$17.0 \pm 1.9$ \\
$24.2 \pm 4.2$
\end{tabular}

All measurements are mean \pm S.E.M. $(n=6)$.

*Denotes a significant difference between heat shock and control within the sampling time period; \#denotes a significant difference between 4-h control fish and 1-h control fish ( $P<0.05$, two-way ANOVA).

AsAT, aspartate aminotransferase; LDH, lactate dehydrogenase. 


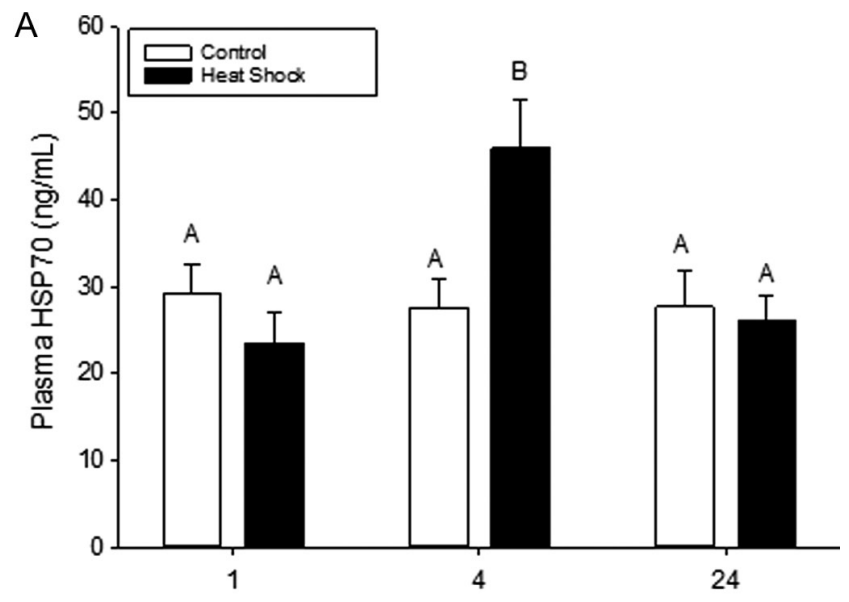

B Time Post Heat Shock (h)

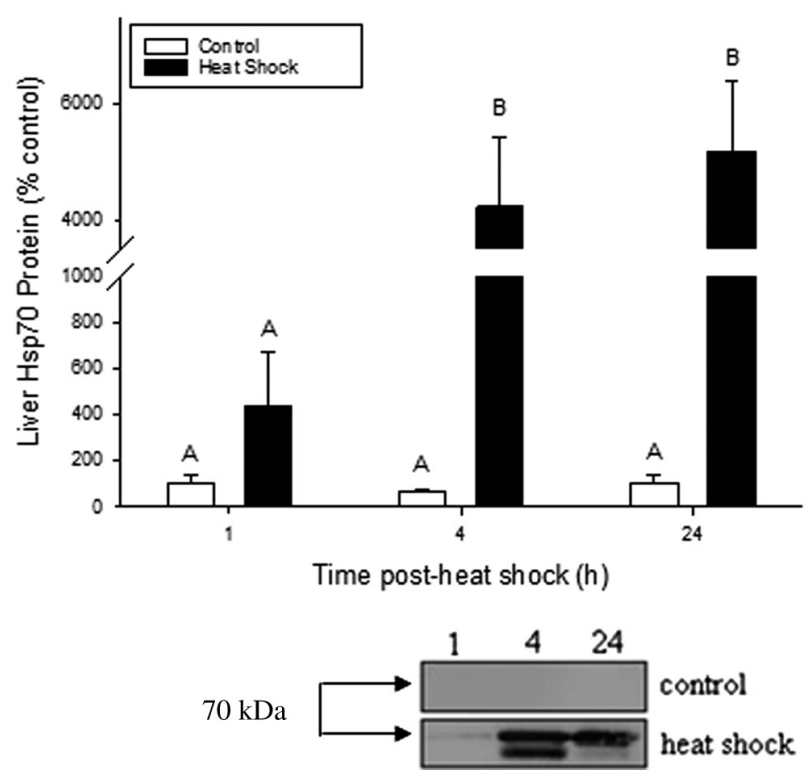

Figure 4

Plasma and liver Hsp70. Trout were exposed to a $1 \mathrm{~h}$ heat shock $\left(+12^{\circ} \mathrm{C}\right.$ above ambient temperature) and then allowed to recover at ambient temperature $\left(13^{\circ} \mathrm{C}\right)$. Samples were collected at 1,4 and $24 \mathrm{~h}$ after heat shock. Plasma Hsp70 protein levels (A) in rainbow trout was determined by ELISA (primary antibody polyclonal rabbit anti-salmonid Hsp70: 1:20,000). Hsp70 expression was examined by immunodetection (primary antibody: polyclonal rabbit anti-salmonid Hsp70: 1:1000) in the liver (B). Values represent means \pm S.E.M. ( $n=3-6$ independent fish); bars with different letters are significantly different $(P<0.05$, two-way ANOVA), a representative western blot of Hsp70 expression in the control and heat shocked liver at 1, 4 and $24 \mathrm{~h}$ after heat shock is shown below the liver histogram.

\section{Discussion}

Our results demonstrate for the first time the presence of exosomes in fish circulation, and these extracellular vesicles were enriched with Hsp70. Although the tissue sources of the circulating exosomes are unknown, our results for the first time, in any model organism, suggest a role for the stress hormone cortisol in modulating Hsp70 expression in exosomes derived from trout hepatocytes. The focus of Hsp70-enriched exosomes in mammalian models, including humans, has been primarily as a potential biomarker for cancer (Gobbo et al. 2016). However, a recent study proposed a physiological role for exosomal Hsp70 enrichment in the organismal cross-tissue protein homeostasis (Takeuchi et al. 2015). The presence of circulating Hsp70-positive exosomes in human (Kalra et al. 2013, Cheng et al. 2014, Vicencio et al. 2015) and fish plasma (this paper), as well as in non-vertebrate species (Takeuchi et al. 2015) underscores the export of Hsp70 via exosomes as a highly conserved response. This together with our finding that plasma Hsp70 levels are transiently modulated after an acute heat stressor in vivo in rainbow trout underscores a physiological role for this exosomal protein in the organismal stress response.

Trout plasma exosomes were confirmed by established markers (Savina et al. 2002, 2003), including vesicular size with TEM and enrichment of the membrane-bound enzyme AChE. Exosomes are approximately $50-100 \mathrm{~nm}$ in diameter (Colombo et al. 2014), and the presence of membrane-bound vesicles was confirmed in trout plasma $(\sim 50 \mathrm{~nm})$ by TEM (Fig. 1B). The other routinely used marker is AChE, and this enzyme was first identified in exosomes released from reticulocytes (Johnstone et al. 1987). Although the exosome payload consists of a suite of proteins, including AChE, beta-actin and Hsp70 and may reflect the tissue of origin (Mathivanan \& Simpson 2009, Mathivanan et al. 2010, Colombo et al. 2014), enrichment of AChE has been considered an excellent indicator of membrane-bound vesicles in circulation (Savina et al. 2002, 2003, Lancaster \& Febbraio 2005, Merendino et al. 2010). This is because AChE-enriched exosomes are predominantly released from hematopoietic cells and may be abundant in circulation, given its important role in the immune response (Gastpar et al. 2005). Consequently, enrichment of AChE in trout plasma exosomes supports the presence of vesicles derived from hematopoietic cells (Fig. 1C), suggesting a role for these exosomes in the fish immune response.

A key finding was that Hsp70 was highly enriched in the exosome fraction of trout plasma (Fig. 2) and in supernatants from hepatocyte cultures (Fig. 3B). Hsp70 is expressed in most cells studied to date in fish (Deane $\&$ Woo 2011). Although Hsp70 enrichment in exosomes was reported in the conditioned media from Atlantic salmon head kidney leukocytes (Iliev et al. 2010), our study is the first to show the enrichment of Hsp70 in

Published by Bioscientifica Ltd 
exososmes in fish plasma in vivo, as well as its modulation by stressors. Although the source of this Hsp70-enriched exosomes is hard to predict, clearly leukocytes (Iliev et al. 2010) and hepatocytes (present study) are involved in the extracellular vesicular release in fish. Teleost hepatocytes have been well characterized for their heat shock response, as well as the modulation of Hsp70 in response to cortisol stimulation (Faught \& Vijayan 2016). Using this model cell system, we demonstrate for the first time the release of Hsp70-enriched exosomes as part of the heat shock response in trout hepatocytes (Fig. 3B). Cortisol reduced this exosomal Hsp70 content suggesting a role for this stress hormone in the modulation of extracellular Hsp70 protein levels during stress. As acute heat shock elevates plasma cortisol levels at the organismal level (Basu et al. 2001, Table 1), we propose that cortisol may be affecting the release of exosomes from target tissues, and this may be the reason for the reduced Hsp70 expression, independent of heat shock, in exosomes released from hepatocytes. This was further supported by the observation that exosomal beta-actin expression was also reduced in a similar fashion to Hsp70 with cortisol treatment (Fig. 3C). Clearly studies are warranted to quantify exosomal release during stress in fish, and in the current study, this was limited by the availability of a robust marker, unlike in mammalian systems (Colombo et al. 2014), for exosomal sorting by flow cytometry. Based on our results, either Hsp70 or beta-actin may be a suitable candidate for exosomal sorting, and this remains to be verified.

Using plasma Hsp70 level as a proxy for exosome abundance, we show for the first time a transient elevation in plasma Hsp70 content in response to an acute heat shock. Although the presence of Hsp70 in extracellular fluids, including blood is well established (see reviews by Calderwood et al. 2007, De Maio 2011), this study supports the modulation of this protein in vivo by an acute heat stressor in fish. Hsp70 in plasma exosomes of rats were reported to be associated with the exosomal membranes and act as a signaling molecule in cardiomyocytes (Vicencio et al. 2015). Specifically, exosomal Hsp70 provided cardioprotection by increasing phosphorylation of protein kinases (ERK $1 / 2$ and Akt), suggesting a regulatory role of exosomes during cardiac stress (Vicencio et al. 2015, reviewed by Ibrahim \& Marbán 2016). Additionally, it was reported that exosomal Hsp70 was necessary to reduce protein aggregation characteristic of polyglutamate disease in vitro (Neuro $2 \mathrm{~A}$ cells) and in vivo (Drosophila; Takeuchi et al. 2015). Consequently, exosomal Hsp70 is thought to play an important role in cross-tissue stress protection and to maintain protein homeostasis (Takeuchi et al. 2015).

The extracellular increase in Hsp70 levels in response to heat shock in the present study was not due to cell lysis as there were no differences in the plasma levels of markers of cell lysis, including AspAT and LDH (Bury et al. 1997).

The temporal profile of the elevated plasma Hsp70 response resembles the liver expression of this protein after a heat shock suggesting increased secretion of Hsp70-enriched exosomes. However, plasma Hsp70 levels approach basal levels by $24 \mathrm{~h}$ despite the tissue Hsp70 content remaining elevated at $24 \mathrm{~h}$ after heat shock (Fig. 4A and B). This suggests regulation of tissue Hsp70 content release or increased turnover of this protein after a stress in fish. As the plasma cortisol levels were higher in the heat-shocked group only at 4 and $24 \mathrm{~h}$ compared to the controls (Table 1), we propose that this steroid may be playing a role in the transient modulation of plasma Hsp70 content after stress. Specifically, the observation that cortisol reduces Hsp70-enriched exosomes from hepatocytes in vitro (Fig. 3B), leads us to propose a role for this steroid in reducing plasma Hsp70 content after a heat shock, and this may include a reduction in exosomal release from target tissues. The physiological implications associated with exosome regulation by cortisol in response to stress remains to be determined. Although the mechanism of cortisol action on vesicular sorting is unknown, this steroid modulates liver plasma membrane fluidity in trout (Dindia et al. 2012). Target cell membrane properties are thought to be involved in exosomal release because GW4869, an inhibitor of neutral sphingomyelinases (nSMase) in mammals, inhibits exosome release (Takeuchi et al. 2015). Inhibition of nSMase prevents the catabolism of sphingomyelin to ceramide, a lipid signaling intermediate known to decrease membrane fluidity (Krönke 1999) and essential for endosomal sorting (Trajkovic et al. 2008). Indeed, the release of exosomes from mammalian hepatocyte is modulated by stressors, including ethanol, a membrane fluidizer (Momen-Heravi et al. 2015, Nojima et al. 2016).

In conclusion, we identified exosomes in trout plasma in vivo and in media from hepatocytes in vitro. These exosomes were enriched in the stress protein Hsp70, and this protein was subsequently used as a marker of vesicular release in response to an acute heat shock in rainbow trout in vivo. Acute stress and the associated increase in the stress hormone cortisol, has the potential to modulate exosome abundance and/or its Hsp70 content. To the 
best of our knowledge, cortisol modulation of exosomes has not been reported in any other organism. Overall, Hsp70-positive exosomes may be playing an important role as intercellular communication signal during stress. Taken together, this study underscores an important, but yet uncharacterized, role for exosome signaling in the organismal stress response.

\section{Declaration of interest}

The authors declare that there is no conflict of interest that could be perceived as prejudicing the impartiality of the research reported.

\section{Funding}

Funding for this work came from the Natural Sciences and Engineering Research Council of Canada (NSERC) discovery grant to MMV.

\section{Acknowledgements}

$E F$ is the recipient of the NSERC-PGS graduate scholarship.

\section{References}

Ackerman PA, Forsyth RB, Mazur CF \& Iwama GK 2000 Stress hormones and the cellular stress response in salmonids. Fish Physiology and Biochemistry 23 327-336. (doi:10.1023/A:1011107610971)

Andreu Z \& Yáñez-Mó M 2014 Tetraspanins in extracellular vesicle formation and function. Frontiers in Immunology 5 442. doi:10.3389/ fimmu.2014.00442

Basu N, Nakano T, Grau EG \& Iwama GK 2001 The effects of cortisol on heat shock protein 70 in two fish species. General and Comparative Endocrinology 124 97-105. (doi:10.1006/gcen.2001.7688)

Basu N, Todgham AE, Ackerman PA, Bibeau MR, Nakano K, Schulte PM \& Iwama GK 2002 Heat shock protein genes and their functional significance in fish. Gene 295 173-183. (doi:10.1016/S03781119(02)00687-X)

Boone AN \& Vijayan MM 2002 Glucocorticoid-mediated attenuation of the hsp70 response in trout hepatocytes involves the proteasome. American Journal of Physiology: Regulatory, Integrative and Comparative Physiology 283 R680-R687. doi:10.1152/ajpregu.00125.2002

Bury NR, McGeer JC, Eddy FB \& Codd GA 1997 Liver damage in brown trout, Salmo trutta L., and rainbow trout, Oncorhynchus mykiss (Walbaum), following administration of the cyanobacterial hepatotoxin microcystin-LR via the dorsal aorta. Journal of Fish Diseases 20 209-215. (doi:10.1046/j.1365-2761.1997.00292.x)

Calderwood SK, Mambula SS, Gray PJ \& Theriault JR 2007 Extracellular heat shock proteins in cell signaling. FEBS Letters 581 3689-3694. (doi:10.1016/j.febslet.2007.04.044)

Cheng L, Sharples RA, Scicluna BJ \& Hill AF 2014 Exosomes provide a protective and enriched source of miRNA for biomarker profiling compared to intracellular and cell-free blood. Journal of Extracellular Vesicles 3 1-14. (doi:10.3402/jev.v3.23743)

Clayton A, Turkes A, Navabi H, Mason MD \& Tabi Z 2005 Induction of heat shock proteins in B-cell exosomes. Journal of Cell Science $\mathbf{1 1 8}$ 3631-3638. (doi:10.1242/jcs.02494)

Colombo M, Raposo G \& Thery C 2014 Biogenesis, secretion and intercellular interactions of exosomes and other extracellular

http://joe.endocrinology-journals.org

DOI: $10.1530 / J O E-16-0427$
(C) 2017 Society for Endocrinology Printed in Great Britain vesicles. Annual Review of Cell and Developmental Biology 30 255-289. (doi:10.1146/annurev-cellbio-101512-122326)

De Boeck G, De Wachter B, Vlaeminck A \& Blust R 2003 Effect of cortisol treatment and/or sublethal copper exposure on copper uptake and heat shock protein levels in common carp, Cyprinus carpio. Environmental Toxicology and Chemistry 22 1122-1126. (doi:10.1002/ etc.5620220521)

De Maio A 2011 Extracellular heat shock proteins, cellular export vesicles, and the stress observation system: a form of communication during injury, infection, and cell damage: It is never known how far a controversial finding will go! Dedicated to Ferruccio Ritossa. Cell Stress and Chaperones 16 235-249. (doi:10.1007/s12192-010-0236-4)

Deane EE \& Woo NYS 2011 Advances and perspectives on the regulation and expression of piscine heat shock proteins. Reviews in Fish Biology and Fisheries 21 153-185. (doi:10.1007/s11160-010-9164-8)

Dindia L, Murray J, Faught E, Davis TL, Leonenko Z \& Vijayan MM 2012 Novel nongenomic signaling by glucocorticoid may involve changes to liver membrane order in rainbow trout. PLOS ONE 7 e46859. (doi:10.1371/journal.pone.0046859)

Dindia L, Faught E, Leonenko Z, Thomas R \& Vijayan MM 2013 Rapid cortisol signaling in response to acute stress involves changes in plasma membrane order in rainbow trout liver. American Journal of Physiology: Endocrinology and Metabolism 304 E1157-E1166. doi:10.1152/ajpendo.00500.2012

Ellman GL 1958 A colormetric method for determining low concentration of mercaptans. Archives of Biochemistry and Biophysics 74 443-450. (doi:10.1016/0003-9861(58)90014-6)

Faught E \& Vijayan MM 2016 Mechanisms of cortisol action in fish hepatocytes. Comparative Biochemistry and Physiology Part B: Biochemistry and Molecular Biology 199B 136. (doi:10.1016/j. cbpb.2016.06.012)

Gastpar R, Gehrmann M, Bausero MA, Asea A \& Gross C 2005 Heat shock protein 70 surface-positive tumor exosomes stimulate migratory and cytolytic activity of natural killer cells migratory and cytolytic activity of natural killer cells. Cancer Research 65 5238-5247. (doi:10.1158/0008-5472.CAN-04-3804)

Gobbo J, Marcion G, Cordonnier M, Dias AMM, Pernet N, Hammann A, Richaud S, Mjahed H, Isambert N, Clausse V, et al. 2016 Restoring anticancer immune response by targeting tumor-derived exosomes with a HSP70 peptide aptamer. Journal of the National Cancer Institute 108 1-11. doi:10.1093/jnci/djv330

Hunter-Lavin C, Davies EL, Bacelar MMFVG, Marshall MJ, Andrew SM \& Williams JHH 2004 Hsp70 release from peripheral blood mononuclear cells. Biochemical and Biophysical Research Communications 324 511-517. (doi:10.1016/j.bbrc.2004.09.075)

Ibrahim A \& Marbán E 2016 Exosomes: fundamental biology and roles in cardiovascular physiology. Annual Review of Physiology 78 67-83. (doi:10.1146/annurev-physiol-021115-104929)

Iliev DB, Jørgensen SM, Rode M, Krasnov A, Harneshaug I \& Jørgensen JB 2010 CpG-induced secretion of MHCIIbeta and exosomes from salmon (Salmo salar) APCs. Developmental and Comparative Immunology 34 29-41. (doi:10.1016/j.dci.2009.07.009)

Ings JS, Servos MR \& Vijayan MM 2011 Hepatic transcriptomics and protein expression in rainbow trout exposed to municipal wastewater effluent. Environmental Science and Technology 45 2368-2376. (doi:10.1021/es103122g)

Iwama GK, Vijayan MM, Forsyth RB \& Ackerman PA 1999 Heat shock proteins and physiological stress in fish. Integrative and Comparative Biology 39 901-909. doi:10.1093/icb/39.6.901

Johnstone RM, Adam M, Hammonds JR \& Turbide C 1987 Vesicle formation during reticulocyte maturation. Journal of Biological Chemistry 262 9412-9420.

Kalra H, Adda CG, Liem M, Ang CS, Mechler A, Simpson RJ, Hulett MD \& Mathivanan S 2013 Comparative proteomics evaluation of plasma exosome isolation techniques and assessment of the stability of 
exosomes in normal human blood plasma. Proteomics 13 3354-3364. (doi:10.1002/pmic.201300282)

Krönke M 1999 Biophysics of ceramide signaling: Interaction with proteins and phase transition of membranes. Chemistry and Physics of Lipids 101 109-121. (doi:10.1016/S0009-3084(99)00059-6)

Lancaster GI \& Febbraio MA 2005 Exosome-dependent trafficking of HSP70: a novel secretory pathway for cellular stress proteins. Journal of Biological Chemistry 280 23349-23355. (doi:10.1074/jbc.M502017200)

Mambula SS, Stevenson MA, Ogawa K \& Calderwood SK 2007 Mechanisms for Hsp70 secretion: crossing membranes without a leader. Methods 43 168-175. (doi:10.1016/j.ymeth.2007.06.009)

Mathivanan S \& Simpson RJ 2009 ExoCarta: a compendium of exosomal proteins and RNA. Proteomics 9 4997-5000. (doi:10.1002/ pmic.200900351)

Mathivanan S, Ji H \& Simpson RJ 2010 Exosomes: extracellular organelles important in intercellular communication. Journal of Proteomics $\mathbf{7 3}$ 1907-1920. (doi:10.1016/j.jprot.2010.06.006)

McCready J, Sims JD, Chan D \& Jay DG 2010 Secretion of extracellular hsp90alpha via exosomes increases cancer cell motility: a role for plasminogen activation. BMC Cancer 10 294. (doi:10.1186/14712407-10-294)

Merendino AM, Bucchieri F, Campanella C, Marcianò V, Ribbene A, David S, Zummo G, Burgio G, Corona DF V, De Macario EC, et al. 2010 Hsp60 is actively secreted by human tumor cells. PLOS ONE 5 e9247. (doi:10.1371/journal.pone.0009247)

Mittelbrunn M, Gutiérrez-Vázquez C, Villarroya-Beltri C, González S, Sánchez-Cabo F, González MÁ, Bernad A \& Sánchez-Madrid F 2011 Unidirectional transfer of microRNA-loaded exosomes from $\mathrm{T}$ cells to antigen-presenting cells. Nature Communications 2 282. (doi:10.1038/ ncomms1285)

Momen-Heravi F, Bala S, Kodys K \& Szabo G 2015 Exosomes derived from alcohol-treated hepatocytes horizontally transfer liver specific miRNA-122 and sensitize monocytes to LPS. Scientific Reports 59991. (doi:10.1038/srep09991)

Multhoff G 2007 Heat shock protein 70 (Hsp70): membrane location, export and immunological relevance. Methods 43 229-237. (doi:10.1016/j.ymeth.2007.06.006)

Nojima H, Freeman CM, Schuster RM, Japtok L, Kleuser B, Edwards MJ, Gulbins E \& Lentsch AB 2016 Hepatocyte exosomes mediate liver repair and regeneration via sphingosine-1-phosphate. Journal of Hepatology 64 60-68. (doi:10.1016/j.jhep.2015.07.030)

Rana S \& Zöller M 2013 The functional importance of tetraspanins in exosomes. In Emerging Concepts of Tumor Exosome-Mediated Cell-Cell Communication, pp 69-106. Ed H-G Zhang. New York, NY, USA: Springer New York. (doi:10.1007/978-1-4614-3697-3)
Sandhu N \& Vijayan MM 2011 Cadmium-mediated disruption of cortisol biosynthesis involves suppression of corticosteroidogenic genes in rainbow trout. Aquatic Toxicology 103 92-100. (doi:10.1016/j. aquatox.2011.02.011)

Savina A, Furlán M, Vidal M \& Colombo MI 2003 Exosome release is regulated by a calcium-dependent mechanism in K562 cells. Journal of Biological Chemistry 278 20083-20090. (doi:10.1074/jbc.M301642200)

Savina A, Vidal M \& Colombo MI 2002 The exosome pathway in K562 cells is regulated by Rab11. Journal of Cell Science 115 2505-2515.

Specker JL \& Anderson TR 1994 Developing an ELISA for a model protein - vitellogenin. In Biochemistry and Molecular Biology of Fishes Volume 3: Analytical Techniques, pp 567-578. Amsterdam, The Netherlands: Elsevier.

Takeuchi T, Suzuki M, Fujikake N, Popiel HA, Kikuchi H, Futaki S, Wada K \& Nagai Y 2015 Intercellular chaperone transmission via exosomes contributes to maintenance of protein homeostasis at the organismal level. PNAS 112 E2497-E2546. (doi:10.1073/pnas.1412651112)

Thery C, Boussac M, Veron P, Ricciardi-Castagnoli P, Raposo G, Garin J \& Amigorena S 2001 Proteomic analysis of dendritic cell-derived exosomes: a secreted subcellular compartment distinct from apoptotic vesicles. Journal of Immunology 166 7309-7318. (doi:10.4049/ jimmunol.166.12.7309)

Thery C, Clayton A, Amigorena S \& Raposo G 2006 Isolation and characterization of exosomes from cell culture supernatants. Current Protocols in Cell Biology 30:3.22:3.22.1-3.22.29. (doi:10.1002/0471143030.cb0322s30)

Trajkovic K, Hsu C, Chiantia S, Rajendran L, Wenzel D, Wieland F, Schwille P, Brügger B \& Simons M 2008 Ceramide triggers budding of exosome vesicles into multivesicular endosomes. Science $\mathbf{3 1 9}$ 1244-1247. (doi:10.1126/science.1153124)

Vicencio JM, Yellon DM, Sivaraman V, Das D, Boi-Doku C, Arjun S, Zheng Y, Riquelme JA, Kearney J, Sharma V, et al. 2015 Plasma exosomes protect the myocardium from ischemia-reperfusion injury. Journal of the American College of Cardiology 65 1525-1536. (doi:10.1016/j.jacc.2015.02.026)

Vijayan MM, Aluru N \& Leatherland JF 2010 Stress response and the role of cortisol. In Fish Diseases and Disorders Volume 2: NonInfectious Disorders, 2nd ed, pp 182-201. Eds JF Leatherland \& P Woo. Oxfordshire, UK: CABI.

Zhang A, Zhou X, Wang X \& Zhou H 2011 Characterization of two heat shock proteins (Hsp70/Hsc70) from grass carp (Ctenopharyngodon idella): evidence for their differential gene expression, protein synthesis and secretion in LPS-challenged peripheral blood lymphocytes. Comparative Biochemistry and Physiology: Part B, Biochemistry and Molecular Biology 159 109-114. (doi:10.1016/j.cbpb.2011.02.009)

Received in final form 30 October 2016

Accepted 16 November 2016

Accepted Preprint published online 21 November 2016 http://joe.endocrinology-journals.org DOI: $10.1530 / J O E-16-0427$
๑) 2017 Society for Endocrinology Printed in Great Britain
Published by Bioscientifica Ltd. 